\title{
Representações Sociais da Depressão e do Suicídio Elaboradas por Estudantes de Psicologia
}

\author{
Social representations of depression and \\ suicide elaborated by psychology students
}

Representaciones sociales de la depresión y del suicidio elaboradas por estudiantes de psicología

Kay Francis Leal Vieira

Maria da Penha de Lima Coutinho

Universidade Federal da Paraíba

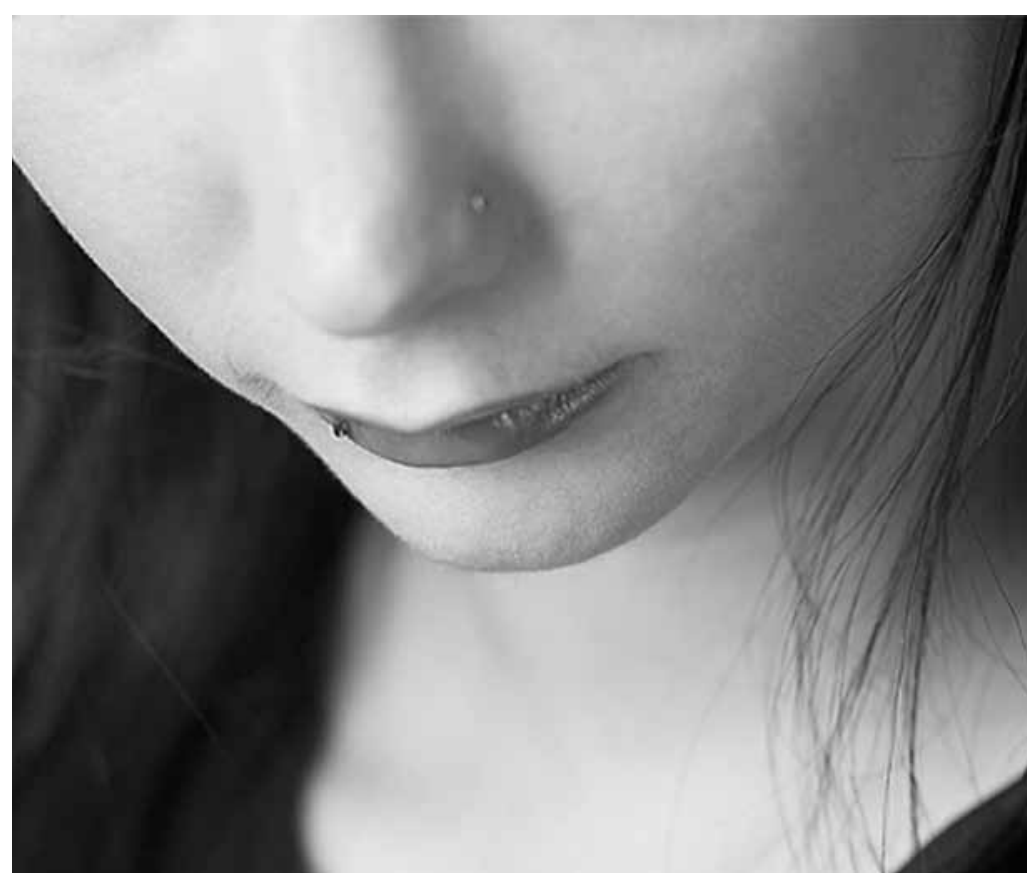


Resumo: O presente estudo aborda a depressão e o suicídio, dois sérios problemas de saúde pública, sob um enfoque psicossociológico, com o objetivo de apreender as representações sociais acerca desses dois fenômenos bem como de investigar a sua ocorrência no meio acadêmico. Participaram da pesquisa 233 estudantes de ambos os sexos, matriculados em todos os períodos do curso de Psicologia de uma universidade pública. Os instrumentos utilizados foram o inventário de depressão de Beck (BDI), a escala de ideação suicida de Beck (BSI) e a técnica de associação livre de palavras, tendo sido usados três estímulos indutores: depressão, suicídio, eu-mesmo. A depressão foi ancorada em elementos psico-afetivos, enquanto o suicídio foi objetivado pelo elemento morte, que representava uma fuga. A auto-imagem dos estudantes, de uma forma geral, emerge de forma positiva, contrastando, porém, com o significativo índice de depressão e ideação suicida encontrado na população estudada.

Palavras-chave: Representações sociais. Depressão. Suicídio. Estudantes de Psicologia.

Abstract: The following study deals with depression and suicide, two serious public health problems, under a psychosocial approach. Its aim is the assimilation of the social representations concerning these two phenomena as well as the investigation of their occurrence in an academic setting. Two-hundred and twenty-three students of both sexes, registered in all periods of the Psychology course of a public university participated in the research. The tools used were Beck's depression inventory (BDI), Beck's suicidal ideation scale (BSI) and the free technique of word association, with the use of three inductive stimulations: depression, suicide, myself. Depression was anchored on psycho-affective elements, whereas suicide was represented by the element death, that meant an escape. The self-image of the students, in general, emerges in a positive way, contrasting however with a significant index of depression and suicidal ideation in this population.

Keywords: Social representations. Depression. Suicide. Psychology students.

Resumen: El presente estudio aborda la depresión y el suicidio, dos serios problemas de salud pública, bajo un enfoque psicosociológico, con el objetivo de aprehender las representaciones sociales acerca de estos dos fenómenos así como de investigar su ocurrencia en medio académico. Participaron de la pesquisa 233 estudiantes de ambos sexos, matriculados en todos los períodos del curso de Psicología de una universidad pública. Los instrumentos utilizados fueron el inventario de depresión de Beck (BDI), la escala de ideación suicida de Beck (BSI) y la técnica de asociación libre de palabras, habiendo sido usados tres estímulos inductores: depresión, suicidio, yo-mismo. La depresión fue anclada en elementos psico-afectivos, mientras el suicidio fue objetivado por el elemento muerte, que representaba una fuga. La auto-imagen de los estudiantes, de una forma general, emerge de forma positiva, contrastando, sin embargo, con el significativo índice de depresión e ideación suicida encontrado en la población estudiada.

Palabras-clave: Representaciones sociales. Depresión. Suicídio. Estudiantes de Psicología.

Embora não exista nenhum acontecimento ou circunstância que possa prever o suicídio, existem certas vulnerabilidades que tornam alguns indivíduos mais propensos a cometer esse ato do que outros. Dentre essas vulnerabilidades, encontram-se as doenças mentais, com especial destaque para o transtorno depressivo, apontado pela Organização Mundial de Saúde (2000) como responsável por $30 \%$ dos casos de suicídio relatados em todo o mundo.
De acordo com Corrêa e Barrero (2006), a relação entre suicídio e depressão é estreita, a ponto de aquele ser, ainda hoje, considerado por muitos um sintoma ou uma conseqüência exclusiva deste. De fato, a importância da associação entre um e outro é um dos dados mais conhecidos e replicados na literatura psiquiátrica. Além disso, o comportamento suicida é freqüentemente considerado um dos sintomas característicos, senão específico, da depressão, mesmo nos grandes sistemas 
De acordo com Vega-Piñero et al. (2002), cerca de $15 \%$ dos depressivos falecem por suicídio, havendo maior risco quando esses indivíduos desenvolvem também sintomas psicóticos, especialmente se estes são atípicos ou incongruentes com o estado de ânimo. nosográficos de classificação, como o CID 10, ou em escalas e inventários internacionalmente conhecidos para avaliação dos sintomas depressivos, como o inventário de depressão de Beck.

Apesar da inexistência de consenso sobre os índices de indivíduos depressivos que chegam a cometer o suicídio, a literatura específica reconhece a influência dessa patologia sobre o comportamento suicida. De acordo com Vega-Piñero et al. (2002), cerca de $15 \%$ dos depressivos falecem por suicídio, havendo maior risco quando esses indivíduos desenvolvem também sintomas psicóticos, especialmente se estes são atípicos ou incongruentes com o estado de ânimo.

Segundo Ballone (2003), os sintomas depressivos mais associados ao suicídio dizem respeito ao severo prejuízo da auto-estima, aos sentimentos de desesperança eà incapacidade de enfrentar e resolver problemas. Esses sintomas podem não estar presentes no início do quadro, mas à medida que a depressão vai se tornando mais grave, a baixa da auto-estima vai piorando, vão surgindo sentimentos de inutilidade e, progressivamente, o indivíduo vai ficando mais desesperado.

Durkheim (2003), em sua obra O Suicídio, destaca a influência da depressão sobre o ato suicida quando define os tipos de suicídio nos estados psicopáticos. O suicídio melancólico, segundo ele, relaciona-se geralmente a um estado de extrema depressão, de exagerada tristeza, que faz com que o doente já não consiga mais apreciar de maneira sadia as relações que com ele têm as pessoas e as coisas que o cercam.

Na atualidade, os fenômenos da depressão e do suicídio encontram-se cada vez mais presentes em todos os espaços sociais, rompendo barreiras de idade, sexo, classe socioeconômica ou cultural, sendo ambos considerados sérios problemas de saúde pública. O transtorno depressivo ocasiona um sofrimento psíquico que interfere, significativamente, na diminuição da qualidade de vida, da produtividade e da capacitação social do indivíduo.

Segundo a OMS, desde a década de 1990, a depressão vem ocupando uma posição de destaque no rol dos problemas de saúde coletiva, sendo considerada a quarta doença mais onerosa de todas as doenças em todo o mundo. Desde o seu surgimento, vem sendo conceituada e classificada de modo diferente, com a adoção de parâmetros, autores e escolas distintas que suscitam controvérsias com relação ao termo. No senso comum, o termo designa desde alterações psicológicas simples e perturbações psiquiátricas graves a flutuações de humor ou de caráter, podendo designar tanto um estado afetivo normal quanto um sintoma, uma síndrome, uma doença ou várias doenças (Coutinho, 2005).

A depressão emerge como resultante de uma inibição global da pessoa, e afeta a função da mente, altera a maneira como a pessoa vê o mundo, sente a realidade, entende as coisas e manifesta suas emoções. Desse modo, segundo Camon (2001), é considerada uma doença do organismo como um todo, que compromete o ser humano na sua totalidade, sem separação entre o psíquico, o social e o físico. Segundo Coutinho e Saldanha (2005), a sua manifestação acaba por se refletir no relacionamento interpessoal, principalmente na estrutura familiar, e vem provocar, muitas vezes, situações de conflito e incompreensão.

De acordo com a OMS, a depressão tem uma prevalência de $17 \%$, e atinge adultos, crianças, ou idosos em algum momento de suas vidas. Segundo Versiani (2004), embora possa ocorrer 
em episódios - de longa ou curta duração ou apenas uma vez na vida de uma pessoa, a depressão é considerada uma doença crônica, mais incapacitante que males como diabetes ou insuficiência cardíaca.

Assim como a depressão, o suicídio vem sendo considerado um grave problema de saúde pública, uma vez que representa uma questão que se agrava a cada dia, traduzindose em índices extremamente significativos. $\mathrm{O}$ comportamento suicida é classificado, com freqüência, em três categorias: ideação suicida, tentativa de suicídio e suicídio consumado. Apesar de haver poucos dados disponíveis, alguns estudos clínicos e epidemiológicos sugerem a presença de um possível gradiente de severidade e de heterogeneidade entre essas diferentes categorias. Assim, num dos extremos, tem-se a ideação suicida (pensamentos, idéias, planejamento e desejo de se matar) e, no outro, o suicídio consumado, com a tentativa de suicídio entre eles (Werlang, Borges, \& Fensterseifer, 2005).

Não existe uma definição única aceitável para o suicídio, mas, quase sempre, sua definição implica necessariamente um desejo consciente de morrer e a noção clara de que o ato executado pode resultar na morte. Neste estudo, suicídio é entendido como o ato de pôr um fim à própria vida, a exemplo do que preconiza Durkheim, que define esse fenômeno como "todo o caso de morte que resulta direta ou indiretamente de um ato positivo ou negativo praticado pela própria vítima, ato que a vítima sabia dever produzir esse resultado" (Durkheim, 2003, p.15).

A taxa mundial de suicídio, segundo dados da OMS (2000), é estimada em torno de 16 por 100 mil habitantes, com variações conforme sexo, idade e país. Acredita-se que as tentativas de suicídio sejam 20 vezes mais freqüentes que os suicídios consumados. De acordo com Pietro e Tavares (2005), observou-se um aumento de $60 \%$ nos índices de suicídio nas ultimas décadas, considerando-se os dados do mundo inteiro.

A morte por suicídio passou a ocupar a terceira posição entre as causas mais freqüentes de falecimento na população de 15 a 44 anos, sendo os jovens considerados como o grupo de maior risco. A taxa oficial de mortalidade por suicídio, no Brasil, é estimada em 4,1 por 100 mil habitantes para a população como um todo, e está, para o sexo masculino, em torno de 6,6 por 100 mil e, para o sexo feminino, em 1,8 por 100 mil (Prieto \& Tavares, 2005).

De acordo com Holmes (2001), as mulheres são três vezes mais propensas a tentarem o suicídio do que os homens, embora os homens sejam três vezes mais propensos a serem bem sucedidos em suas tentativas. A razão para essa diferença ainda não está bem definida, mas acredita-se que isso se deva ao fato de as mulheres serem mais propensas a sofrerem de depressão do que os homens, reconhecendo-se, assim, o importante papel desempenhado por essa patologia frente aos atos suicidas. Porém, uma outra hipótese também é destacada para explicar essa diferença entre homens e mulheres: os homens usam técnicas mais violentas (por exemplo, armas de fogo ou branca e jogar-se de altura) do que as mulheres (por exemplo, overdose, corte dos pulsos, ingestão de medicamentos), o que aumenta, assim, as chances de as tentativas serem bem-sucedidas.

As estatísticas sobre os atos suicidas são falhas e subestimadas, uma vez que o número de suicídios que consta nas estatísticas oficiais é extraído das causas de morte assinaladas nos atestados de óbito. Esses atestados, porém, 
nem sempre são confiáveis, uma vez que a família e a própria sociedade comumente pressionam para que a causa seja mascarada. De acordo com Cassorla (1998), certamente a subestimação estatística será mais intensa quando se trata de crianças e adolescentes, em que os atos autodestrutivos serão negados ou até escondidos pela família, diante de maiores sentimentos de culpa e/ou vergonha pelo ato. Além disso, uma grande proporção de suicídios é confundida com acidentes, principalmente quando se trata de crianças e adolescentes. Outro fator complicador nas estatísticas é que não temos meios de verificar os suicídios inconscientes, dentre eles os acidentes e as doenças (Cassorla, 1992).

Para o desenvolvimento do presente estudo, utilizou-se o aporte teórico/metodológico das representações sociais (TRS), desenvolvida pelo francês Serge Moscovici (Moscovici, 1978), partindo do pressuposto de que essa teoria possibilita a construção de um conhecimento socialmente partilhado que permita ao grupo de afiliação elaborar uma prática acerca das representações da depressão e do suicídio na inserção do seu contexto.

A teoria das representações sociais é uma forma sociológica de Psicologia social que surgiu com a publicação do estudo La Psychanalyse: Son Image et Son Public (Moscovici, 1961). Segundo Farr (1998), ela difere, marcadamente, das formas psicológicas de Psicologia social, que são atualmente predominantes nos Estados Unidos da América. Esse contraste ocorre entre uma tradição de pesquisa européia e uma americana de Psicologia social moderna.

Segundo Jodelet (2001), a representação social é: ...uma forma de conhecimento, socialmente elaborada e partilhada, com um objetivo prático, e que contribui para a construção de uma realidade comum a um conjunto social. Igualmente, designada como saber de senso comum ou ainda saber ingênuo, natural, essa forma de conhecimento é diferenciada, entre outras do conhecimento científico. (p. 22)

A origem desse conceito provém de estudos realizados por Durkheim, no campo da Sociologia, sob a denominação de representação coletiva. Em 1912, quando publica As Formas Elementares da Vida Religiosa, ele elabora o conceito de representações coletivas, em que propõe um conjunto sistemático de elementos que tentam explicar uma multiplicidade de fenômenos sociais (Nóbrega, 2001).

Moscovici (1978) busca explicar como os pensamentos se estruturam e se organizam em relação ao contexto social. Para tanto, ele acrescenta novos elementos às idéias contidas na teoria da representação coletiva, fazendo com que a noção de representação social se situe na fronteira entre a Psicologia e a Sociologia. A representação social referese, pois, à maneira de o indivíduo pensar e interpretar o cotidiano, ou seja, constitui um conjunto de imagens e é dotada de um sistema de referência que o permite interpretar sua vida e a ela dar sentido.

A elaboração e funcionamento de uma representação podem ser compreendidos através dos processos de objetivação e ancoragem, que compreendem a imbricação, a articulação entre a atividade cognitiva e as condições sociais em que são forjadas as representações (Coutinho, 2005).

Segundo Jodelet (2001), a objetivação é o processo pelo qual o indivíduo reabsorve um excesso de significações, materializando-as, ou seja, é o processo de construção formal de um 
conhecimento pelo indivíduo. Já a ancoragem, como instrumento do saber, é uma modalidade que permite compreender como os elementos de representação não só exprimem relações sociais mas também contribuem para construílas. A ancoragem, portanto, assegura o elo entre a função cognitiva de base da representação e a sua função social e fornece à objetivação os elementos imaginativos que irão servir para a elaboração de novas representações.

Inicialmente, conforme o modelo proposto por Moscovici, em 1978, as representações sociais possuíam duas funções: formação de condutas e orientação das comunicações sociais. Posteriormente, Abric (1994) acrescentou outras duas funções às representações, justificadas pela evolução das pesquisas realizadas a propósito das cognições e práticas sociais: a função identitária, que permite salvaguardar a imagem positiva do grupo e sua especificidade, e a função justificadora, que permite aos atores manterem ou reforçarem os comportamentos de diferenciação social nas relações entre grupos (Nóbrega, 2001).

Segundo Vala e Monteiro (2004), as representações sociais apresentam uma dimensão funcional e prática, que acaba por ser evidente na organização dos comportamentos, das atividades comunicativas, na argumentação e na explicação cotidianas e na diferenciação dos grupos sociais. Desse modo, identificar as representações sociais acerca da depressão e do suicídio é compreender as formas que as pessoas utilizam para criar, transformar e interpretar essas problemáticas vinculadas à sua realidade como também conhecer seus pensamentos, sentimentos, percepções e experiências de vida compartilhadas, destacadas nas modalidades diferenciadas de comunicação, de acordo com o contexto cultural e a classe social a que pertencem, e as instituições às quais se está vinculado, que se prolongam para além das dimensões intrapsíquicas e se concretizam em fenômenos sociais possíveis de serem identificados e mapeados (Coutinho, 2005).

Estudar esses dois eixos temáticos ancorados nas representações sociais significa estudálos não apenas através dos aportes teóricos, normativos e científicos, mas com vistas a um novo olhar, voltado para a construção de um conhecimento prático e compartilhado por um determinado grupo de pertença (Coutinho, 2005, Coutinho \& Saldanha, 2005).

Apreender as representações sociais dos acadêmicos de Psicologia acerca da depressão e do suicídio significa compreender os processos de classificação e nomeação que permitem entender os transtornos psicoafetivos do anonimato e ancorá-los numa rede de significação a partir do consenso desse grupo. Em seu ambiente social, são veiculadas as crenças, opiniões e sentimentos acerca desses eixos temáticos entre o grupo de pertencimento.

Compreende-se aqui que estudar as representações sociais é buscar conhecer o modo como um grupo humano, neste estudo, os estudantes de Psicologia, constroem um conjunto de saberes acerca de determinado objeto, no caso, a depressão e o suicídio. $\mathrm{O}$ referencial teórico da teoria das representações sociais é aqui adotado enfatizando um saber real que contribui para o entendimento de como indivíduos, futuros profissionais da Psicologia, dão significado às temáticas pesquisadas através de suas representações.

Face ao exposto, foi objetivo desta pesquisa apreender as representações sociais dos universitários do curso de Psicologia de uma universidade pública acerca da depressão e do suicídio bem como investigar a existência desses fenômenos no meio acadêmico. 


\section{Método}

O presente estudo trata de uma pesquisa de campo, subsidiado em uma abordagem multimétodo de cunho qualitativo e quantitativo, aprovado pelo Comitê de Ética em Pesquisa do Centro de Ciências da Saúde, da Universidade Federal da Paraíba - CCS / UFPB sob o protocolo no 441, em 31/05/2006, conforme a Resolução CNS/MS no 196/96.

\section{Participantes}

A amostra foi do tipo não-probabilística, intencional e acidental, constituída por 233 estudantes do curso de Psicologia, de ambos os sexos, regularmente matriculados em uma universidade pública, e que cursavam do 1 응 ao último período.

\section{Instrumentos}

Para obtenção dos dados, foram utilizados os seguintes instrumentos: inventário de depressão de Beck (BDI), a escala de ideação suicida de Beck (BSI) e o Teste de Associação Livre de Palavras.

BDI (Beck Depression Inventory) é a sigla pela qual é universalmente conhecido o instrumento inventário de depressão de Beck para medida da intensidade da depressão, um dos primeiros recursos dimensionais desse tipo. O BDI foi originalmente criado por Beck, Ward, Mendelson, Mock e Erbaugh (1961) e revisado por Beck, Rush, Shaw e Emery (1979/1982). É uma escala de auto-relato, de 21 itens, cada um com quatro alternativas, subentendendo graus crescentes de gravidade da depressão, com escores de 0 a 3 (Cunha, 2001). É indicado para sujeitos de 17 a 80 anos, embora sejam citadas pesquisas desenvolvidas aquém e além desse período etário. Na literatura há também várias referências a estudos em amostras de adolescentes.

A escala de ideação suicida de Beck - BSI é constituída por 21 itens; os primeiros 19 itens, apresentados com três alternativas de respostas, refletem gradações da gravidade de desejos, atitudes e planos suicidas. Os dois últimos itens, não incluídos no escore final, de caráter informativo, fornecem importantes subsídios sobre o paciente a respeito do número de tentativas prévias de suicídio e da seriedade da intenção de morrer na última delas.

A BSI foi estruturada de forma a permitir que os cinco primeiros itens possam ser usados como triagem da ideação suicida. Assim sendo, se a resposta do examinado for 0 ao grupo de afirmações 4 - "indicando ausência de intenção ativa" - ou ao grupo de numero 5 - "indicando evitação de morte, se confrontado com uma situação ameaçadora para a vida" - ele deverá ser orientado a passar imediatamente ao item 20, deixando de dar resposta aos 14 seguintes (Cunha, 2001). Tais itens são mais específicos a respeito de planos e atitudes, com uma intenção suicida subjacente; caso tenha havido qualquer escolha diferente de 0 , no item 4 ou 5, o examinando fará escolhas referentes aos grupos de afirmações dos itens 6 a 19. Quanto ao item 20, deve ser respondido por todos os examinandos, tenham ou não preenchido os 14 itens anteriores. Já o item 21 só será respondido por sujeitos com história de alguma tentativa prévia de suicídio.

O Teste de Associação Livre de Palavras, originalmente desenvolvido por Jung na prática clínica, teve como objetivo realizar diagnóstico psicológico sobre a estrutura da personalidade do sujeito. Esse teste foi adaptado ao campo da Psicologia social por Di Giacomo (1981), e 
desde então vem sendo amplamente utilizado nas pesquisas sobre as representações sociais.

Nóbrega e Coutinho (2003) destacam que, diferentemente dos objetivos clínicos de Jung, os pesquisadores em representações sociais visam a identificar as dimensões latentes nas RS através da configuração dos elementos que constituem a trama ou rede associativa dos conteúdos evocados em relação a cada estímulo indutor.

O Teste de Associação Livre de Palavras é um tipo de investigação aberta que se estrutura através da evocação de respostas dadas a partir de um ou mais estímulos indutores. Esses estímulos indutores devem ser previamente definidos em função do objeto a ser pesquisado ou do objeto da representação, levando-se também em consideração as características da amostra ou os sujeitos da pesquisa.

\section{Procedimentos}

Inicialmente, foi feito um contato prévio com os professores das disciplinas do curso, que concordaram em ceder um tempo de suas aulas para que os estudantes participassem da pesquisa. A fase de coleta de dados foi realizada nos meses de outubro a dezembro de 2006, de forma coletiva, com os alunos em suas respectivas salas de aula.

Os participantes foram previamente informados a respeito dos objetivos e procedimentos da pesquisa bem como da confiabilidade dos dados e do anonimato da sua colaboração. Em seguida, foi-lhes solicitado que assinassem o Termo de Consentimento Livre e Esclarecido, de acordo com as normas da Resolução no196/96 sobre Pesquisa Envolvendo Seres Humanos.
Os instrumentos foram aplicados na seguinte ordem: Teste de Associação Livre de Palavras, inventário de depressão de Beck (BDI) e, por fim, a escala de ideação suicida de Beck (BSI).

Os dados obtidos através da técnica de associação livre de palavras foram processados pelo software Tri-Deux-Mots e interpretados por meio da análise fatorial de correspondência (AFC). Esse procedimento fornece uma representação gráfica composta por eixos ou fatores (F1 e F2)12, que revelam a atração obtida entre as variáveis fixas e as variáveis de opiniões, formadas pelas respostas de associação dos participantes face aos estímulos indutores. Foram utilizados como estímulos indutores: depressão (estímulo 1), suicídio (estímulo 2) e eu mesmo (estímulo 3), e as variáveis fixas utilizadas foram: período do curso, faixa etária e sexo.

Os dados apreendidos pelo inventário de depressão de Beck (BDI) foram analisados seguindo-se os critérios de corte para os diferentes níveis de depressão, proposto por Cunha (2001), conforme a classificação a seguir: 0-9 $\rightarrow$ depressão mínima;10-16 $\rightarrow$ depressão leve; 17-29 $\rightarrow$ depressão moderada; $30-63 \rightarrow$ depressão severa.

Os resultados apreendidos através desse instrumento foram analisados com auxílio do programa estatístico SPSS, versão 13.0.

A análise dos dados obtidos pela escala de ideação suicida de Beck - BSI foi feita mediante as respostas diferentes de zero dadas pelo participante aos itens 4 (que indica ausência de intenção suicida ativa) e 5 (que indica evitação de morte, se confrontado com uma situação ameaçadora para a vida). Sendo assim, foi 
considerada a presença da ideação suicida sempre que os indivíduos deram qualquer resposta diferente de zero nesses dois itens.

A BSI possibilita a análise sob dois pontos de vista: a) a presença ou não da ideação suicida, e b) a intensidade com que cada indivíduo deseja morrer, tem intenções, planos detalhados e se tem em vista um método que o prepare para chegar à execução de um ato suicida e, naturalmente, o grau com que admite isso.

Os resultados apreendidos através desse instrumento também foram analisados com auxílio do programa estatístico SPSS, versão 13.0.

\section{Resultados e discussão}

Perfil dos participantes

Participaram desta pesquisa 233 estudantes do curso de Psicologia, sendo 58 do sexo masculino e 175 do sexo feminino, o que corresponde a pouco mais de $75 \%$ da amostra total. A faixa etária que mais contribuiu para o presente estudo foi a de 17-22 anos, composta por 181 estudantes $(77,6 \%)$. Em relação aos períodos nos quais os participantes estavam matriculados, houve a preocupação de apreender todos os períodos, de modo que fosse possível termos participantes iniciantes (calouros), estudantes do meio do curso e formandos. Participaram 103 estudantes dos primeiros períodos do curso $\left(1 \stackrel{0}{ }, 2^{\circ}\right.$ e

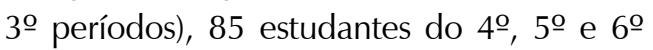
períodos e 55 estudantes do final do curso (70 período em diante). A grande maioria dos participantes da pesquisa era solteira $(95,27 \%)$ e não possuía trabalho remunerado. Em relação à renda familiar, a maioria dos estudantes afirmou possuir uma renda entre quatro a sete salários mínimos. No que se refere à habitação, a maioria dos participantes residia com os pais.
Inventário de Depressão de Beck - BDI

No que diz respeito ao objetivo de identificar o índice epidemiológico da depressão nos estudantes do curso de Psicologia de uma universidade pública, observou-se que, dos 233 estudantes, 25 apresentaram pontuação acima do ponto de corte (16) proposto por Cunha (2001), o que representa um índice de $10,72 \%$ da amostra total.

A partir dos dados apreendidos pelo questionário sociodemográfico, foi possível traçar o perfil desses universitários que pontuaram no inventário de depressão de Beck (BDI), conforme descrito a seguir.

Constatou-se que, do total de estudantes com depressão, $80 \%$ eram do sexo feminino e apenas $20 \%$ do sexo masculino. A maioria (92\%) encontrava-se na faixa etária dos 18 aos 22 anos. Em relação ao estado civil, todos os estudantes afirmaram serem solteiros, e apenas $12 \%$ deles trabalhava. Pouco mais da metade dessa população $(60 \%)$ estava cursando os períodos referentes à metade do curso (4으, $5^{0}$ e $6^{0}$ períodos). No que se refere à renda familiar, observou-se que $32 \%$ dos participantes possuía renda de até três salários mínimos, 36\% possuía renda familiar entre quatro a sete; $32 \%$ afirmou possuir renda entre oito a onze salários mínimos. Quanto à habitação, a maioria dos estudantes deprimidos, ou seja, 44\%, morava com os pais.

Como já foi dito, o BDI é composto por 21 itens, sendo que cada um deles diz respeito a um sintoma característico da depressão. Sendo assim, foi possível apreender os elementos mais significativos dessa patologia para o grupo pesquisado. Os principais elementos representativos da depressão encontrados nos participantes foram os relacionados à tristeza, 
à autocrítica, à insatisfação, à ideação suicida e ao sentimento de culpa. Observou-se que esses elementos são similares aos apontados pela nosologia psiquiátrica como principais sintomas desse transtorno. Nota-se também o aparecimento significativo da ideação suicida, objeto de nossa investigação, como uma das características mais eminentes no quadro depressivo.

O aparecimento da ideação suicida como um dos sintomas mais eminentes nos jovens universitários deprimidos confirma a relação existente entre a depressão e o ato suicida.

Escala de Ideação Suicida de Beck - BSI

Com o objetivo de identificar a presença da ideação suicida nos estudantes de Psicologia, constatou-se, mediante análise dos dados, a presença da ideação suicida em 26 participantes, o que corresponde a $11 \%$ da amostra total dos estudantes.

Detalhando-se os dados apreendidos através do questionário sociodemográfico, foi possível traçar o perfil específico desses estudantes que apresentaram ideação suicida. Destes, observou-se que $63 \%$ eram do sexo feminino e $37 \%$ do sexo masculino; a faixa etária da maioria $(74,1 \%)$ encontrava-se entre 18-22 anos de idade. Em relação ao período do curso, percebeu-se que $30 \%$ dos estudantes com ideação suicida encontrava-se matriculada nos primeiros períodos, $37 \%$ estava cursando os períodos considerados do meio do curso $\left(4^{\circ}, 5^{\circ}\right.$ e 6o períodos) e $33 \%$ eram alunos formandos ou pré-formandos (a partir do 7 o período). No que se refere ao estado civil dos participantes, observou-se que a quase totalidade dos participantes (96,3\%) era solteira, e 88,9\% não trabalhava. Em relação à renda familiar desses estudantes, observou-se que $11,1 \%$ possuía renda familiar de até três salários mínimos,
44,4\%, de quatro a sete salários mínimos, e $44,4 \%$, de oito a onze salários mínimos. É importante ressaltar o valor do salário mínimo na época, que era de $R \$ 350,00$ (trezentos e cinqüenta reais).A respeito da habitação desses indivíduos com ideação suicida, percebeu-se que $11,1 \%$ residia sozinhos, $40,7 \%$ residia com os pais, $33,3 \%$ residia com colegas e $14,8 \%$ afirmou possuir outro tipo de habitação.

Fazendo um paralelo entre os dois instrumentos utilizados neste estudo, observou-se que, do total de estudantes de Psicologia com pensamentos suicida, a maioria $(84,61 \%)$ apresentou sintomatologia depressiva leve, moderada ou severa, o que caracteriza a grande influência da depressão sobre o ato suicida. Entretanto, também foi registrada a presença da ideação suicida em indivíduos que não apresentaram o transtorno depressivo, fato esse que traduz o suicídio como um fenômeno complexo, com causas multivariadas, não podendo, pois, ser resumida única e exclusivamente à existência do transtorno depressivo. Sendo assim, podemos afirmar que o ato suicida é ou a aplicação de uma idéia patológica ou a escolha deliberada de uma pessoa sem patologia mental (Mello, 2000).

Uma outra questão analisada pela BSI diz respeito às tentativas prévias de suicídio, fato esse bastante apontado pela literatura consultada como um fator de risco para o suicídio. A BSI avaliou que, dos 233 participantes, 59,3\% informou nunca ter realizado uma tentativa de suicídio, 37\% tentou se matar uma vez e 3,7\% tentou cometer o suicídio mais de duas vezes ao longo da vida. Esses resultados mostram-se bastante preocupantes, uma vez que se sabe que a tentativa prévia de suicídio é considerada um fator bastante relevante para uma nova tentativa ou mesmo para o suicídio consumado. Desses estudantes que já tentaram cometer o suicídio em algum momento de suas vidas, 
observou-se que $55 \%$ dos mesmos apresentou novamente ideação suicida no momento da realização da coleta dos dados. Ressalta-se aqui a importância da reincidência do comportamento suicida através dos pensamentos recorrentes de morte.

Dos estudantes que já tentaram o suicídio em algum momento de suas vidas, observou-se que mais da metade (55\%) estava mais uma vez apresentando pensamentos de morte, ou seja, apresentou ideação suicida. Esses dados são de suma importância, uma vez que se sabe que a presença da ideação suicida e, principalmente, de uma história positiva de tentativas de suicídio possuem um valor preditivo na avaliação do risco de suicídio (Turecki, 1999).

Teste de Associação Livre de Palavras

A análise dos resultados foi orientada pela leitura do gráfico fornecido pelo software Tri-Deux-Mots, apresentado a seguir:

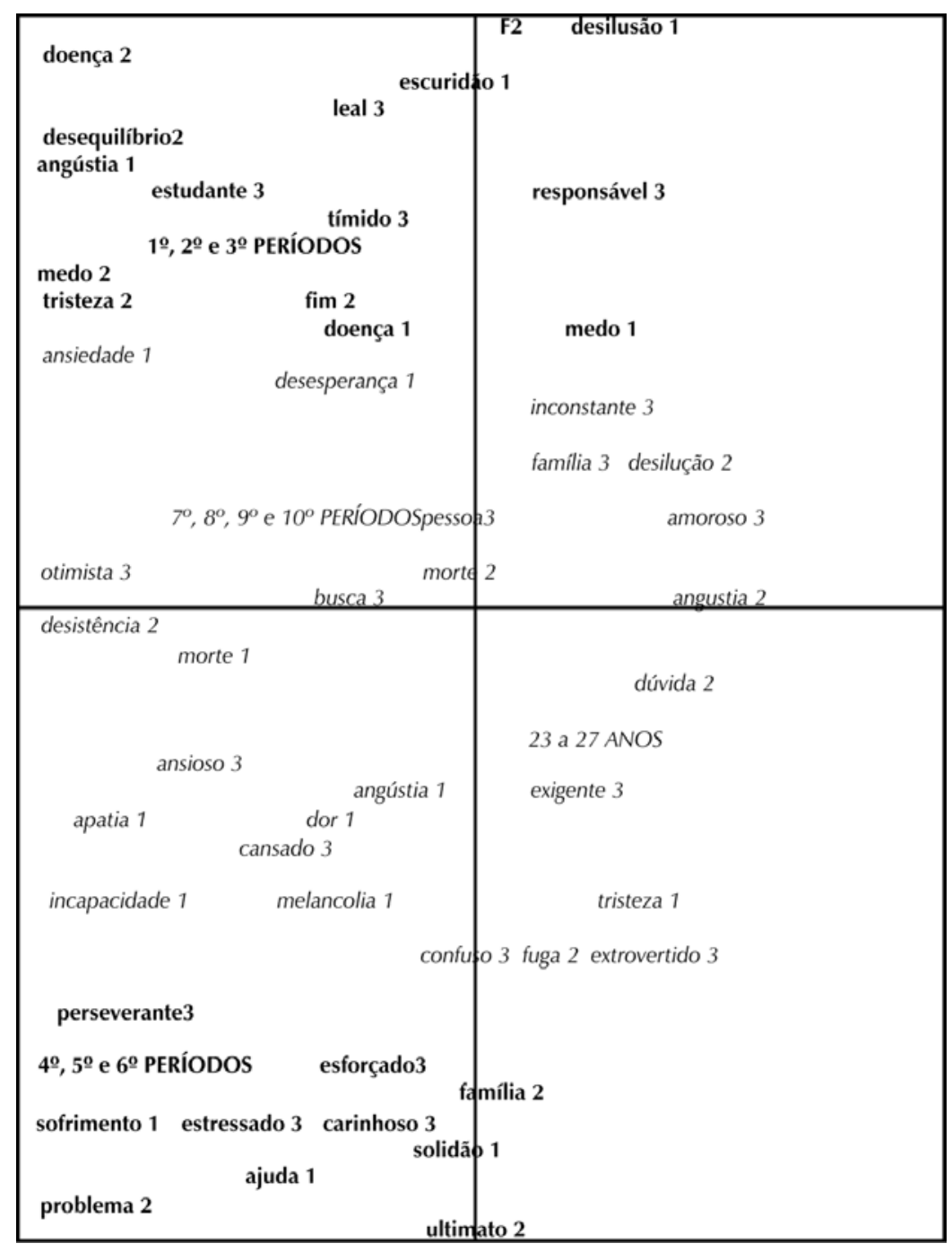

Figura 1. Análise fatorial de correspondência das representações sociais da depressão e do suicídio. 
Em relação ao fator 1, no lado esquerdo do gráfico, em itálico, emergiu o campo semântico elaborado pelos estudantes dos últimos períodos do curso $\left(77^{\circ}, 8^{\circ}\right.$, $9^{\circ}$ e e $10^{\circ}$ o períodos), que se auto-representaram como pessoas otimistas $\_$que se encontram em processo de busca, o que lhes traz cansaço e ansiedade. A depressão foi representada por um conjunto de elementos, sendo entendida como uma tristeza, uma melancolia que gera ansiedade, angústia, dor, apatia e incapacidade e que pode levar à morte. O suicídio também foi objetivado pelo elemento morte, sendo ele motivado por um sentimento de desesperança perante a vida.

Observa-se que, apesar da vivência da transação entre o estudante e o profissional, esses universitários conservam o otimismo durante essa busca por sua identidade profissional. O cansaço ao qual esses estudantes se referem pode estar relacionado ao período no qual os dados foram coletados, ou seja, próximo ao término do período letivo da universidade. Percebe-se que a depressão foi ancorada no conhecimento erudito oriundo da nosologia da Psicologia clínica e da psiquiatria. O elemento morte, presente tanto na objetivação da depressão quanto do suicídio, indica a existência de uma relação entre as representações sociais desses dois fenômenos.

Ainda no fator 1, no lado direito, em oposição às respostas dos participantes matriculados nos últimos períodos do curso, emergiu o campo semântico elaborado pelos estudantes com idades entre 23 a 27 anos, que se autorepresentaram como pessoas extrovertidas, amorosas e ligadas à família. A depressão foi representada como uma tristeza, enquanto o suicídio representa uma fuga, uma desistência da vida diante de uma desilusão.

Observa-se que esse grupo de afiliação se autorepresentou ancorando-se em manifestações sociais, afetivas e comportamentais, com a caracterização de uma auto-imagem positiva. A representação dada à depressão é oriunda da nosologia clínica, destacando-se seu principal elemento, a tristeza. O suicídio, representado como uma fuga, pode ser compreendido como uma saída encontrada pelo indivíduo para a solução de seus problemas.

Em relação ao fator 2, na parte superior, emergiu o campo semântico elaborado pelos estudantes dos primeiros períodos $\left(1 \stackrel{0}{0}, 2^{\mathrm{O}} \mathrm{e}\right.$ 3 o período), que se auto-representaram como estudantes, tímidos e leais. A depressão foi representada como uma doença, causadora de medo, angústia e escuridão, que são decorrentes de uma desilusão na vida da pessoa. O suicídio também foi representado como uma doença, decorrente de um desequilíbrio, que causa medo e tristeza e caracteriza o fim da vida.

Percebe-se que as auto-representações desse grupo foram ancoradas em manifestações próprias de acadêmicos de início de um curso de graduação, enfocando sua timidez, sua lealdade e seu papel social de estudantes. Observa-se também que, para os universitários do início do curso, as representações da depressão e do suicídio são bastante semelhantes, uma vez que os atores sociais utilizaram evocações similares para representarem esses dois fenômenos.

Por contraste, na parte inferior do fator 2, surgiu o campo semântico constituído pelos estudantes do $4 \stackrel{0}{ }, 5^{\circ}$ e $6^{\circ}$ períodos, que se auto-representaram como esforçados, perseverantes e estressados. A depressão foi representada como uma solidão, causadora de um sofrimento psíquico para o qual se deve buscar ajuda. O suicídio foi representado como um ultimato, problema para o qual se faz necessário o apoio da família. 
Observa-se que esses estudantes se auto-representaram ancorando-se em manifestações decorrentes de sua dinâmica acadêmica, indicando dificuldades nesse percurso mas também destacando sua vontade de seguir em frente. A depressão e o suicídio foram ancorados nos sintomas clínicos, em que se enfoca para os dois fenômenos a necessidade da ajuda, no caso do suicídio, uma ajuda mais específica, a da família. Mais uma vez, percebe-se, através das evocações dadas pelos atores sociais, semelhanças entre as representações sociais da depressão e do suicídio.

\section{Considerações gerais}

Conhecer as representações sociais da depressão e do suicídio elaboradas pelos estudantes de Psicologia permite-nos compreender esses fenômenos a partir de um conhecimento socialmente elaborado e partilhado. É possível, pois, conhecer os pensamentos, sentimentos e percepções desse grupo, identificando nessas representações suas crenças, valores e atitudes.

Mediante a análise dos dados coletados, pôdese observar que a depressão foi representada pelos estudantes de forma semelhante à descrição clínica categorizada nos distúrbios psicoafetivos, independentemente das variáveis sociodemográficas pesquisadas. Em relação a essas variáveis, ocorreu o nãoaparecimento da variável sexo, o que indica que as representações sociais dos estudantes a respeito dos estímulos dados não foram significativamente diferentes entre homens e mulheres. Já as variáveis relacionadas ao período no qual o estudante estava inserido, bem como sua faixa etária, apresentaram diferenças significativas em relação aos estímulos estudados.
Percebe-se que as evocações dadas ao estímulo depressão foram muitas vezes as mesmas dadas ao estímulo suicídio, o que significa uma semelhança entre as representações sociais desses dois fenômenos para o grupo pesquisado. O suicídio, objetivado pelo elemento morte, representa para os estudantes uma fuga, uma saída escolhida pelo indivíduo face às adversidades advindas do meio externo.

A auto-imagem dos estudantes, de forma geral, emerge de forma positiva, coincidindo com o que se espera dos acadêmicos de Psicologia. As auto-representações assumem contorno diferenciado em relação ao tempo de vínculo com o curso de Psicologia, ora ancorado em manifestações referentes à proximidade do enfrentamento da realidade profissional, ora concentrando-se em manifestações sociocognitivas.

O índice epidemiológico da depressão, assim como a presença da ideação suicida entre os jovens acadêmicos, demonstra a necessidade de maior atenção a essa população, no sentido de promover diferenciados serviços de apoio psicológico na formação desses futuros profissionais.

No que se refere à aplicabilidade do estudo, acredita-se que a investigação de transtornos como a depressão e a ideação suicida na comunidade acadêmica, especificamente em estudantes de Psicologia, possa levar a maior preocupação com a qualidade de vida e com a formação profissional desses universitários, fazendo-se a proposta de um acesso mais fácil aos serviços de ajuda psicológica da instituição. Além disso, acredita-se também que a compreensão da forma como esses indivíduos vêem e lidam com os fenômenos pesquisados, sob a ótica da teoria das representações sociais, possibilita uma complementaridade entre o saber científico e o senso comum. 


\section{Kay Francis Leal Vieira}

Mestra em Psicologia Social da Universidade Federal da Paraíba

E-mail: kayleal@bol.com.br

\section{Maria da Penha de Lima Coutinho*}

Departamento de Psicologia da Universidade Federal da Paraíba

Doutora em Psicologia pela Universidade de São Paulo e Pós-Doutora pela Universidade Aberta de Lisboa, Portugal

*Endereço para envio de correspondência:

Rua João Soares Padilha, no 21 apto 1103

Bessa, João Pessoa - PB - Brasil

CEP 58.036-835

E-mail: penhalcoutinho@yahoo.com.br

Recebido 20/08/2007 Reformulado 04/04/2008 Aprovado 10/04/2008

Referências PUF.

Ballone, G. J. (2003). Suicídio na adolescência. Disponível em PsiqWeb: psiquiatria geral, em http://www.virtualpsy.org/infantil/suicidio.html

Beck, A. T., Ward, C. H., Mendelson, M., Mock, J., \& Erbaugh, J. (1961). An inventory for measuring depression. Archives of General Psychiatry, 4, 561-571.

Beck, A. T., Rush, A. J., Shaw, B. F., \& Emery, G. (1982). Terapia cognitiva da depressão. Rio de Janeiro: Zahar.

Camon, V. A. (2001). Depressão e psicossomática. São Paulo: Pioneira Thompson Learning.

Cassorla, R. (1992).O que é suicídio. São Paulo: Brasiliense.

Cassorla, R. (1998). Do suicídio: estudos brasileiros. Campinas, SP: Papirus.

Corrêa, H., \& Barrero, S. P. (2006). Suicídio: uma morte evitável. São Paulo: Atheneu.

Coutinho, M. P. L., \& Saldanha, A. A. W. (2005). Representações sociais e práticas de pesquisa. João Pessoa: Editora Universitária / UFPB.

Coutinho, M. P. L. (2005). Depressão infantil: uma abordagem psicossocial. João Pessoa: Editora Universitária / UFPB

Cunha, J. A. (2001). Manual da versão em português das escalas de Beck. São Paulo: Casa do Psicólogo.

Di Giacomo, J. P. (1981). Aspects méthodologiques de l'analyse de réprésentations sociales. Cahiers de Psychologie Cognitive, 1, 397-422.

Durkheim, E. (2003). O suicídio. São Paulo: Martin Claret

Farr, R. M. (1994). Representações sociais: a teoria e sua história. In P. Guareschi, \& S. Jovchelovtich (Eds.), Textos em representações sociais (pp. 31-55). Petrópolis, RJ: Vozes.

Holmes, D. S. (2001). Psicologia: transtornos mentais. Porto Alegre: ArtMed.

Jodelet, D. (Ed.). (2001). As representações sociais. Rio de Janeiro: Ed. UERJ.
Mello, M. F. (2000). O suicídio e suas relações com a psicopatologia: análise qualitativa de seis casos de suicídio racional. Cadernos de Saúde Pública, 16(1), 163-170.

Moscovici, S. (1978). A representação social da psicanálise. Rio de Janeiro: Zahar.

Moscovici, S. (1961). La Psychanalyse: son Image et son Publi. Paris: Press Universitaires de France.

Nóbrega, S. M., \& Coutinho, M. P. L. (2003). O teste de associação livre de palavras. In Coutinho et al., Representações sociais: abordagem interdisciplinar. João Pessoa: Editora Universitária / UFPB.

Nóbrega, S. M. (2001). Sobre a teoria das representações sociais. In A. Moreira, Representações sociais: teoria e práticas. João Pessoa: Editora Universitária / UFPB.

OMS. The World Health Report 2000. Suicide. Genebra: OMS, 2000. Recuperado em dezembro de 2006, de http://www.who.int/toics/suicide/en

Prieto, D., \& Tavares, M. (2005). Fatores de risco para o suicídio e tentativa de suicídio: incidência, eventos estressores e transtornos mentais. Revista Brasileira de Psiquiatria, 54(2), 146-154

Solomon, A. (2002). O demônio do meio-dia. Rio de Janeiro: Objetiva.

Turecki, G. (1999). O suicídio e sua relação com o comportamento impulsivo-agressivo. Revista Brasileira de Psiquiatria, 21 (supl.2), 18-22.

Vala, J., \& Monteiro, M. B. (2004). Psicologia social. Lisboa: F. C. Gulbenkian.

Vega-Piñero, M. et al. (2002). El suicídio. Salud Global, ano II(4).

Versiani, M. (2004). Depressão: uma doença crônica. Revista Ciência Hoje. Psiquiatria, 34(201), 34-37.

Werlang, B. S. G., Borges, V. R., \& Fensterseifer, L. (2005). Fatores de risco ou proteção para a presença de ideação suicida na adolescência. Revista Interamericana de Psicologia, 39(2), 259266. 